\title{
Emergency department management of an occult renal laceration following a minor fall
}

\author{
Kimberly A. Hubbard*1, Shawn M. Varney² \\ ${ }^{1}$ Department of Pediatrics, University of Arkansas for the Medical Sciences, Little Rock, AR, USA \\ ${ }^{2}$ Department of Emergency Medicine, University of Texas Health - San Antonio, San Antonio, TX, USA
}

Received: December 30, 2020

Accepted: May 16, 2021

Online Published: May 27, 2021

DOI: $10.5430 /$ dcc.v8n1p11

URL: https://doi.org/10.5430/dcc.v8n1p11

\begin{abstract}
We present a case of a pediatric patient with high grade renal injury following a minor fall, where clinical suspicion of occult injury resulted in diagnosis. Additionally, we review the management of high grade renal lacerations in children, including the role of ultrasound in managing these injuries.
\end{abstract}

Key Words: High grade renal laceration, Pediatric renal trauma, Nonoperative management, Ultrasound imaging in renal trauma

\section{INTRODUCTION}

Blunt force trauma may result in life-threatening abdominal injuries, including lacerations of the liver, spleen, or kidneys. The kidneys are the most commonly injured organ in the genitourinary system, occurring primarily in young men. ${ }^{[1]}$ Children are at increased risk for blunt force renal injury due to increased relative renal size and mobility, as well as decreased perirenal fat compared to adults. ${ }^{[2]}$ While rare, high grade renal lacerations are important for physicians staffing pediatric emergency departments to be familiar with, due to evolving management. We present a case of a pediatric patient with high grade renal injury following a minor fall, where clinical suspicion of occult injury resulted in diagnosis. In addition, we review the literature regarding management of these injuries.

\section{CASE REPORT}

A 12-year-old previously healthy male presented to a pediatric clinic for lower left lateral chest wall pain following a minor fall from a four-foot high platform of a backyard playset onto a wheelbarrow. He denied loss of consciousness or other injury, and stated he immediately got up and continued playing. He was not forthcoming with other historical details. The patient vomited twice in clinic but otherwise had no acute complaints. His vital signs were stable, and his examination was remarkable for mild tenderness over the left lateral ribs with two mild abrasions along the left flank at ribs 7 and 10 (see Figure 1). His chest X-ray revealed no acute abnormalities or fracture. Six hours after discharge from the clinic, the patient presented to the emergency department (ED) with gross hematuria, worsening chest wall pain, and eight episodes of vomiting. He denied shortness of breath, difficulty voiding since the inciting event, any history of ureteral stones, or prior episodes of hematuria. Vital signs were as follows: BP 114/70 mmHg, HR 83 beats per minute, RR 19 breaths per minute, $\mathrm{SaO}_{2} 98 \%$ on room air, temperature 98.5F. Physical examination was remarkable for tenderness in the left upper quadrant and left chest

\footnotetext{
* Correspondence: Kimberly A. Hubbard; Email: KAHubbard@uams.edu; Address: University of Arkansas for the Medical Sciences, Pediatric Housestaff Office, 1 Children's Way, Slot 512-19A, Little Rock, AR 72202, USA.
} 
wall, the aforementioned abrasions, and mild costovertebral angle tenderness. His hemoglobin and hematocrit were $11.4 \mathrm{~g} / \mathrm{dl}, 33.7 \%$, respectively, with a platelet count of 247 $\mathrm{K} / \mathrm{mcL}$. An ED bedside Focused Abdominal Sonography for Trauma (FAST) examination revealed left renal abnormalities without evidence of hemoperitoneum. A subsequent CT abdomen/pelvis showed a left lateral mid-kidney laceration with extension into the renal pelvis consistent with a grade 4 renal laceration and a subcapsular hematoma with a small focus of contrast extravasation in the arterial phase (see Figure 2). The patient was admitted to the Trauma service in the Pediatric ICU with a Urology consultation. A CT urogram was performed prior to admission, which showed no injury to the bladder or ureters. A repeat CT urogram obtained 48 hours later was negative for injury to the bladder or ureters and showed slight improvement to a stable renal laceration. The patient remained hemodynamically stable, and his hematuria spontaneously resolved without urologic complications. He was discharged home from the PICU on hospital day three with Urology and Pediatric Trauma followup. At follow-up appointments, the patient was doing well, had no complications, and had returned to normal activity.

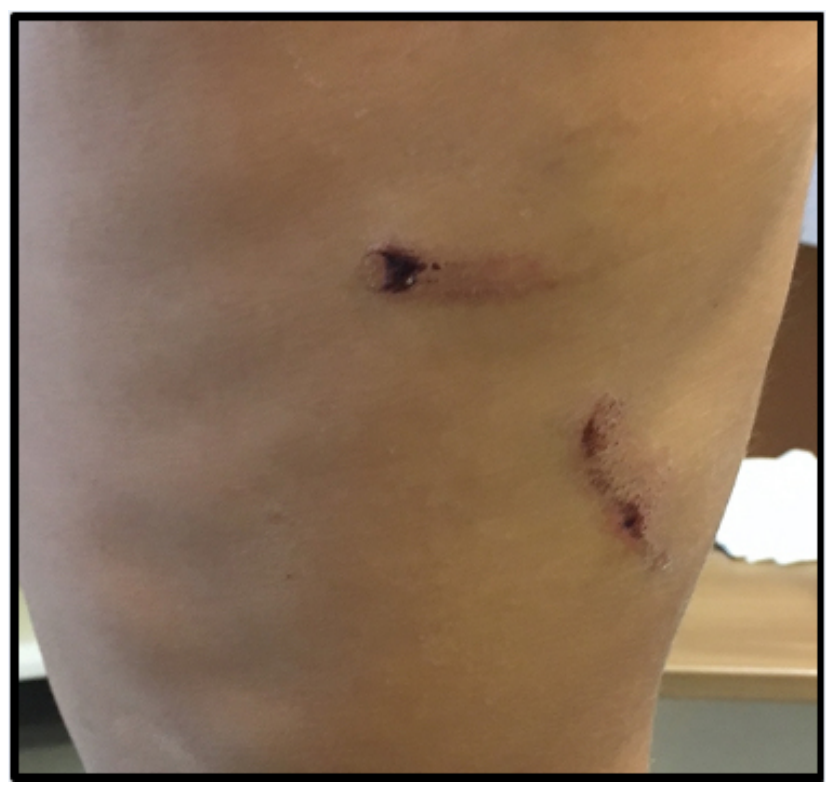

Figure 1. Abrasions to left chest wall

\section{LITERATURE REVIEW}

The management of high grade (grade IV or V) renal lacerations has evolved from a primarily surgical issue to a more conservative approach. High grade renal injuries are defined as lacerations which extend into the renal parenchyma, specifically the collecting system (Grade IV) or multiple lacerations involving the collecting system (Grade V). ${ }^{[3,4]}$ Low grade injuries do not involve the renal collecting system; they vary from a subcapsular hematoma (Grade I) to a cortical laceration less than $1 \mathrm{~cm}$ in depth without extension into the collecting system or evidence of urinary extravasation (Grade III). ${ }^{[3,4]}$ Previously, these injuries involved operative interventions for hemostasis and frequently, nephrectomy of the affected kidney; however, observation has become the new standard, which has increased renal salvage rates and improved long-term patient outcomes. ${ }^{[5]}$ Classically, most low grade lacerations (Grade I-III) are managed with a brief hospital admission for observation, while high grade lacerations (Grade IV-V) usually result in admission to a critical care unit for intensive observation and may require surgical intervention. ${ }^{[6]}$ However, the few lacerations which required surgery were grade $\mathrm{V}$ lacerations. ${ }^{[7]}$ While nearly all grade $\mathrm{V}$ injuries required surgical intervention, most grade IV injuries resolved on their own, with the return of adequate kidney function. ${ }^{[8]} \mathrm{CT}$ scan was the initial imaging modality of choice to risk stratify renal injuries that may require later surgical intervention due to symptomatic urinomas. ${ }^{[9]}$ These injuries had the following CT findings: laceration in the anteromedial portion of the kidney, intravenous contrast extravasation, and large perinephric hematomas. ${ }^{[9]}$ These "high risk" features on initial CT also correlated with patients requiring hemostatic intervention and resulted in aggressive reimaging. ${ }^{[10]}$ While these prognostic features appear promising, further studies are needed to validate their role and reliability. The role of routine reimaging has recently been questioned for stable high grade renal lacerations; reimaging was recommended only for unstable or clinically significant injuries (grade IV renal lacerations with urinary extravasation, in addition to all grade $\mathrm{V}$ injuries). ${ }^{[11]}$ Though used previously, delayed imaging CT was suggested to be unnecessary, but later expert opinion suggested initial delayed imaging CT with ultrasound follow-up for stable renal injuries may be adequate for continuing assessment and thereby reduce radiation exposure. ${ }^{[12,13]}$ While ultrasound has no radiation risk, it lacks the user-to-user sensitivity of a CT scan and should not be used as a diagnostic test as in a FAST exam, though it may be used for reimaging in stable cases. ${ }^{[2]}$ In sum, the management of high grade renal injuries has evolved from primarily surgical to more observational, with an emphasis on risk stratification following initial imaging to identify potentially complex injuries that may require later surgical intervention. Reimaging these injuries to monitor the laceration has also been re-examined, and there may be a growing role for ultrasound in the stable high grade renal laceration.

In sum, there is a growing role for risk stratification of high grade renal injuries to better predict patient outcomes. Conservative management has become the usual care for these injuries, excepting episodes of hemodynamic instability, which 
should proceed directly to surgery for hemostasis and possible nephrectomy. High grade renal injuries may be risk stratified based on characteristics on initial CT scan, which may identify potentially complicated cases, requiring subsequent urologic intervention and aggressive reimaging. Further studies are needed to validate any predictive factors. In children, CT should be the initial scan used for diagnosis and prognosis, but ultrasound may be used as initial screening and follow-up imaging for lower-risk injuries to decrease radiation exposure. Ultimately, conservative management of high grade renal lacerations has increased renal salvage, though improvements may continue through risk stratification and selective use of ultrasound for reimaging.

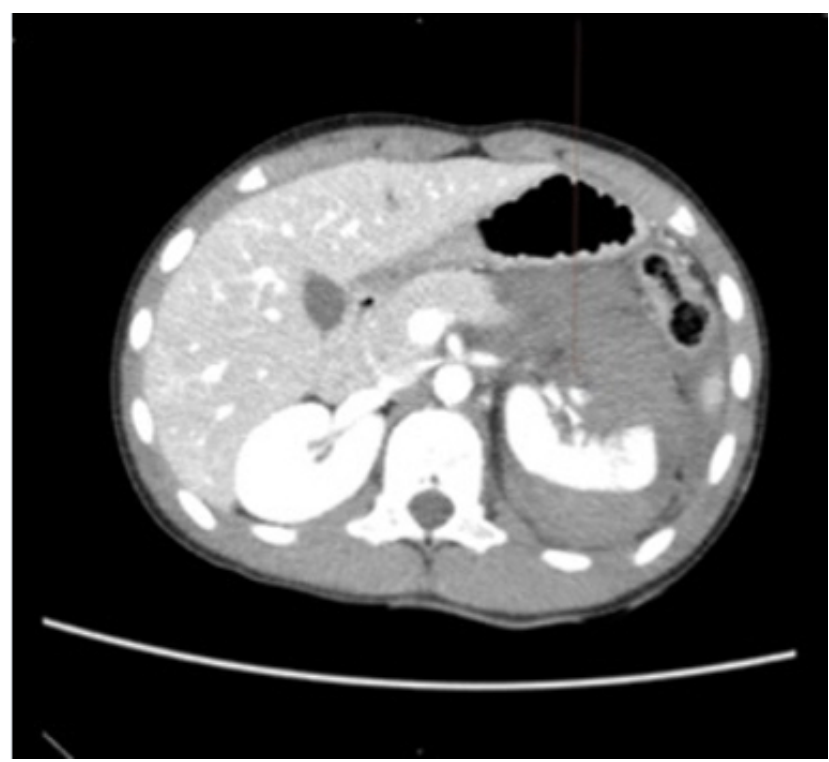

Figure 2. Axial CT showing grade IV renal laceration

\section{Discussion}

Blunt force trauma is a common cause of renal lacerations, as in this patient. Statistically, adolescent males are more likely to present with renal injury secondary to blunt force trauma, and given this patient's presentation, it was reasonable to suspect abdominal injury, particularly in light of a worsening examination and negative chest $\mathrm{x}$-ray. ${ }^{[1]}$ Abdominal assessment is key to early identification of potentially life-threatening injuries to the liver, spleen, or kidneys. ${ }^{[14]}$ While the initial exam and imaging of the patient appeared benign, his worsening clinical status warranted further investigation for acute abdominal processes secondary to the injury. The bedside FAST examination yielded signs of a renal abnormality, which led to a CT scan, and ultimately, the diagnosis. In this case, a high grade renal laceration was unusually isolated, without concomitant injury to the spleen or "high risk" features on CT, so conservative management with observation was standard treatment. While high grade renal lacerations like this case have previously been surgically managed with partial or total nephrectomies, conservative management of high grade renal lacerations is equally effective. ${ }^{[5]}$ Though this patient did receive a followup CT urogram to monitor resolution of his injury, a renal ultrasound may have been sufficient, as the laceration spontaneously resolved without urologic intervention. In this case of a child with an isolated high grade renal laceration following a minor fall, conservative management with supportive care prevented surgery and preserved his kidney.

\section{Conclusion}

Following blunt force abdominal trauma, consider occult renal lacerations, particularly in patients with a worsening abdominal examination despite negative initial imaging. Bedside ultrasound may be used as initial imaging for evaluation of occult injuries, especially if the history is unclear, but CT should be used for diagnosis and management of renal lacerations. The initial CT scan may help identify complicated injuries requiring subsequent surgical intervention for symptomatic urinomas. These complicated lacerations with "high risk" features on initial CT may also require aggressive reimaging, whereas stable high grade renal lacerations without predictive factors on initial CT may be considered "low-risk" and should be managed conservatively. Ultrasound may decrease radiation exposure for re-imaging low-risk injuries, but CT remains the typical imaging modality for follow-up.

\section{CONFLICTS OF INTEREST DISCLOSURE}

The authors declared no conflicts of interest.

\section{REFERENCES}

[1] Paparel P, N'diaye A, Laumon B, et al. The epidemiology of trauma of the genitourinary system after traffic accidents: analysis of a register of over 43,000 victims. BJU International. 2006; 97(2): 338-41. PMid:16430642. https://doi.org/10.1111/j.1464-410X. 20 $06.05900 . \mathrm{x}$

[2] Fernández-Ibieta M. Renal Trauma in Pediatrics: A Current Review.
Urology. 2018; 113: 171-8. PMid:29032236. https://doi.org/ 10.1016/j. urology . 2017.09.030

[3] Bryk DJ, Zhao LC. Guideline of guidelines: a review of urological trauma guidelines. BJU International. 2015; 117(2): 226-34. PMid:25600513. https://doi.org/10.1111/bju. 13040

[4] Moore EE, Moore FA. American Association for the Surgery of Trauma Organ Injury Scaling: 50th Anniversary Review Article 
of the Journal of Trauma. The Journal of Trauma: Injury, Infection, and Critical Care. 2010; 69(6): 1600-1. PMid:21150537. https ://doi.org/10.1097/TA.0b013e318201124e

[5] Henderson C, Sedberry-Ross S, Pickard R, et al. Management of High Grade Renal Trauma: 20-Year Experience at a Pediatric Level I Trauma Center. Journal of Urology. 2007; 178(1): 246-50. PMid:17499798. https://doi.org/10.1016/j.juro.2007.03 .048

[6] Dalton B, Dehmer J, Shah S. Blunt Renal Trauma. Journal of Pediatric Intensive Care. 2015; 04(01): 16-20. PMid:31110845. https://doi.org/10.1055/s-0035-1554984

[7] Broghammer JA, Langenburg SE, Smith SJ, et al. Pediatric blunt renal trauma: Its conservative management and patterns of associated injuries. Urology. 2006; 67(4): 823-827. PMid:16566992. https://doi.org/10.1016/j.urology.2005.11.062

[8] Rogers CG, Knight V, Macura KJ, et al. High-grade renal injuries in children-is conservative management possible? Urology. 2004; 64(3): 574-9. PMid:15351596. https://doi.org/10.1016/j.urolog y. 2004.04.069

[9] Lee JN, Lim JK, Woo MJ, et al. Predictive factors for conservative treatment failure in grade IV pediatric blunt renal trauma. Journal of Pediatric Urology. 2016; 12(2). PMid:26292911. https: //doi.org/10.1016/j.jpurol.2015.06.014
[10] Dugi DD, Morey AF, Gupta A, et al. American Association for the Surgery of Trauma Grade 4 Renal Injury Substratification Into Grades 4a (Low Risk) and 4b (High Risk). Journal of Urology. 2010; 183(2): 592-7. PMid:20018329. https://doi.org/10.1016/j.juro.2 009.10 .015

[11] Tomasz Z, Piotr P, Ryszard S, et al. Validity of routine reimaging of blunt renal trauma managed conservatively. Medicine. 2019; 98(14). PMid:30946385. https://doi.org/10.1097/MD.00000000000 15135

[12] Fuchs ME, Beecroft N, Dajusta DG, et al. Is Delayed Phase Computed Tomography Imaging Necessary After Blunt Renal Trauma in Children? Urology. 2017; 113: 187-91. PMid:29174941. https : //doi.org/10.1016/j.urology. 2017.11.017

[13] Johnsen NV, Voelzke BB. Re: Fuchs et al.: Is Delayed Phase Computed Tomography Imaging Necessary After Blunt Renal Trauma in Children? (Urology 2017; 113: 187-191). Urology. 2018; 115: 195-196. PMid:29452140. https://doi.org/10.1016/j.urol ogy . 2018.01 .042

[14] Guareschi BLV, Stahlschmidt CMM, Becker K, et al. Epidemiological analysis of polytrauma patients with kidney injuries in a university hospital. Revista Do Colégio Brasileiro De Cirurgiões. 2015; 42: $382-$ 5. PMid:26814990. https://doi.org/10.1590/0100-6991201 5006006 